\title{
Experiments and Observations made at the Plymouth Laboratory.
}

By

\section{J. T. Cunningham, M.A.}

I. Diagnostic Characters in Flat Fishes
II. The Development of the Egg in Flat Fishes and Pipe-fishes
III. A Piebald Plaice

\section{Diagnostic Characters in Flat Fishes.}

ONE of the objects of zoological study is to ascertain more completely and more accurately the peculiarities by which one kind of animal (species, variety, genus, \&c.) is distinguished from another. The advance of our knowledge in this direction depends on the more minute examination and more accurate distinction of known forms, the examination of larger numbers of specimens from familiar localities, and the examination of specimens from localities previously unsearched. There is scarcely any family so thoroughly investigated that it does not yield new discoveries on a renewed examination of more abundant material. It is found possible to recognise finer distinctions, and so split up one species into several, or convert what was considered a species into a genus. New material-that is to say, examination of a large number of specimensoften shows, too, that distinct species are more or less connected by intermediate forms. But in all this work the part played by these minute peculiarities in the life of the animal usually receives little attention. It is not the object of systematic zoology to ascertain the uses of characters, or to explain their origin. These objects require different methods, and are usually pursued by different NEW SERIES. - VOL. III, NO. IV. 
investigators. But among the various methods employed there is one which has seldom, if ever, been followed-that of surveying the various characters of different grades,-specific, generic, family, \&c. -in order to find whether it is possible to trace a connection between them and the habits of the animals which exhibit them, and generally to consider how far the principles which have been suggested in explanation of the evolution of species are applicable to the diagnostic characters of a particular family. On the present occasion I propose to consider the family of flat fishes. This Journal is, I think, not the place for a paper entirely devoted to developing arguments or presenting evidence in support of particular views or conclusions of a theoretical character. Therefore, although my inclination to certain views may be obvious in the following remarks, I have no desire to press these views on this occasion ; but my object is merely to describe certain observations and studies I have recently made, and to point out what an immense field of interesting inquiry is afforded in the relations and development of those characters by which the subdivisions of a single family of fishes are distinguished.

My own observations have been for the most part confined to British specimens of the family of flat fishes; and for a general survey of the characters throughout the family, and their relations to one another, I shall rely chiefly on a valuable paper by the American ichthyologists, Jordan and Goss, published in 1889.* Certain kinds of flat-fish are distinguished by the fact that the dorsal and ventral fins are prolonged on to the lower side of the body at the base of the tail, the attachments of these accessory portions being transverse to the axis of the body. One of the fish that present this character is not uncommon round all the coasts of Britain; at Plymouth specimens are frequently obtained, either in the Sound in summer, or on more distant grounds. This is the Zeugopterus punctatus of Collett, the Muller's topknot of Couch, Rhombus hirtus of Yarrell. The chief other characteristics of this fish are its almost rectangular shape, the posterior region of the body being much broader and less triangular than in other flat fishes, the roughness of the upper side of the body, due to the character of the scales, and the presence of a large foramen in the septum between the gill-cavities. The great breadth of the body posteriorly is due partly to the breadth of the body proper, partly to that of the dorsal and ventral fins, in which the fin-rays are longest near the posterior end, so that the outer edges of the fins form a straight line transversely across the base of the tail. The snout is obtuse, and the trunk and dorsal fin rise steeply behind it, giving

* A Reviev of the Flounders and Soles (Pleuronectidæ) of America and Europe, by David Starr Jordan and David Kop Goss; Rep. U.S. Fish Commission for 1886 (1889). 
the rectangular form anteriorly. The scales are short from before backwards and broad transversely; the exposed portion is short, and projects outwards from the skin at an angle with the embedded portion; at the edge is a single row of spines, of which the central one is considerably the longest. These spines are not of the same length in all the scales, but longer ones occur at scattered points over the skin.

Only two other kinds of flat fishes are known in which what may be called subcaudal finlets are present; or, to put the same fact in other words, the fishes in which this character is present are separated by other differences into three species. The other two are Zeugopterus unimaculatus, Steenstrup, and Zeugopterus norvegicus (Günther). The former is distinguished by the fact that the first ray of the dorsal fin is produced into an elongated filament, while in the latter this character is wanting, and the pelvic fins are separate from the ventral, not united with it as in punctatus. The other specific characters consist in minor differences in the generic characters themselves. The perforation of the branchial septum exists also in Arnoglossus megastoma, commonly called the megrim at Plymouth; and in consequence of this Steenstrup included this species with the three previously mentioned in the genus Zeugopterus. But as this last species does not possess the subcaudal prolongations of the dorsal and ventral fins, nor the other characters which unite the first three, it is best to confine the name Zeugopterus to these three species.

The three species of Zeugopterus, then, have what may be described as a continuous distribution. No two of them are geographically separated, and they have not been found anywhere beyond a limited region on the coast of Europe. All three occur on the British coasts. Punctatus is, as has been stated, frequently taken in Plymouth Sound; it occurs all along the south coast of England, and also on the east coast. It has been taken on the east coast of Scotland as far north as the Orkneys, on the west coast of Scotland in the Firth of Clyde, and on the east coast of Ireland. Northward the species extends to the north coast of Norway, southward to the northern shores of France, but it is absent from the Mediterranean. Norvegicus is likewise a northern form, not ranging to the Mediterranean. I have taken several specimens at Plymouth : one specimen was taken during the survey of fishing grounds on the west coast of Ireland, 1891-2 ; three specimens have been taken in the Clyde. It is somewhat rare on the Scandinavian coasts. Unimaculatus, on the other hand, is a Mediterranean form, occasionally but rarely taken on British and northern coasts. I have never sbtained a specimen at Plymouth. On the south-west coast of Scot- 
land it is more abundant than at any other part of the British coasts, several specimens having been taken in Loch Fyne and the Firth of Clyde. It has been taken on the coast of Denmark, but not on that of Norway.

Peculiar habits, differing from those of other flat fishes, have been observed in living specimens of two species of Zeugopterus, namely, punctatus and unimaculatus. The fish are seen in aquaria to be nearly always adhering to the vertical sides, remaining in one place for a long time, and keeping themselves suspended in this way in a vertical position without any difficulty. Other flat fishes occasionally assume this position, but are unable to retain it for more than a few seconds or minutes. This habit was studied by the late $\mathrm{Mr}$. George Brook, F.Z.S., who described his observations in two papers.* In the first of these he refers only to Zengopterus unimaculatus, of which he took several specimens in Loch Fyne in a small sandy bay. They usually adhered to the sides of the tank in which they were placed, although found on this sandy ground overgrown with Zostera or seagrass. The body was slightly raised from the glass with the lower surface of the unpaired fins tightly pressed against it. A current of water is stated to have passed from the branchial chamber of the lower side along the space between the body and the glass and out behind, this current being caused by a rapid vibratory movement of the accessory portions of the dorsal and anal fins. The accessory portions of the fins appeared, therefore, "to be specially constructed to aid in the respiratory function." In his later paper Brook states that he was inclined to think he laid too much stress on the action of the accessory flap. " "The basal portions of the vertical fins are kept in constant motion, but this motion is more vigorous in the rays immediately in front of the tail than in the accessory flaps situated underneath it." Brook did not attempt to explain the method by which the fish was enabled to adhere to the glass or other vertical surface and maintain itself in a vertical position.

My own observations in the Plymouth Laboratory have been made on Z. punctatus, and my object was to ascertain what force kept the fish in a vertical position against a vertical surface, and how the force was produced. The fish lives well in confinement, and is not timid or violent in its movements when disturbed. It is not difficult, therefore, to guide it to the glass front of the tank and persuade it to adhere there, so that observations and experiments can be made with it. It was evident that the adhesion of the fish was not produced by ordinary sucker action-in other words, by hydrostatic pressure, because the space beneath the body was freely open to the outside water in front dorsally

* Ichthyological Notes, Fourth Ann. Rep. Scot. Fishery Board; Notes on the British Species of Zeugopterus, Proc. Roy. Phys. Soc. Edinb., Session 1886-7. 
and ventrally to the head. The posterior parts of the fin-fringes were in constant motion, moving in a series of vibrations from before backwards, together with the part of the body to which they were attached, and the effect of this motion was to pump out the water from the space between the body and the glass, its place being supplied by water which entered in front. The subcaudal fin-flaps were perfectly motionless, and tightly pressed between the base of the tail and the surface of the glass, so that any movement of them was impossible. The question arose, however, whether the tail and these flaps formed a small sucker which helped in the adhesion. To test this I removed the flaps with a snip of the scissors, an operation which caused very little pain to the fish, and it adhered afterwards quite as well as when the flaps were in their natural condition. The subcaudal flaps are therefore certainly not necessary to the adhesion, nor to the pumping action of the muscles and fins, which went on as before. It seemed probable, therefore, that the pumping action was itself the cause of the adhesion. But the difficulty in accepting this view was that there was a distinct though gentle respiratory movement of the jaws and opercular flaps ; and if the pumping of the water from beneath the body caused a negative pressure there, and a positive pressure on the outer side of the body, it seemed equally certain that the respiratory movement must force water into the space beneath the body, and so cause a positive pressure there which would tend to force the fish away from the glass. The currents of water were now examined by means of the suspended particles in the water, and by putting carmine from a pipette at any spot at which it was desired to see the rapidity and direction of the flow. Particles were seen to pass in at the mouth and out at the lower respiratory orifice, but particles and carmine were also seen to pass into the space beneath the body above and below the head without passing through the respiratory channel. It was, therefore, satisfactorily proved that the amount of water pumped out in a given time at the sides of the tail was greater than the amount passed in anteriorly by the respiratory movements; and considerably greater, for the velocity of the stream above and below the snout as shown by the movement of the particles of carmine was by no means insignificant. It follows that the pumping action of the fins, continually withdrawing water from the space between the body and the surface to which it is applied, causes a negative pressure greater than the positive pressure due to the respiratory movements, and this keeps the body pressed against the vertical surface sufficiently to prevent its falling. The negative pressure is continually being neutralised by the water entering in front, and therefore the pumping action must be constantly kept up, as it is observed to be. 
The direct resistance which prevents the fish from falling under the action of gravity is, of course, friction ; but unless there was some force to press the fish against the solid surface there would be no friction. In testing the currents with carmine it was seen to pass in at the mouth and out at both gill openings and nothing was observed which indicated a special part played by the perforation of the gillseptum.

To test the validity of the explanation I had arrived at concerning the adhesion of the fish, I constructed a model in the following manner. I took a rectangular piece of flexible thin sheet india rubber. In the middle of each of the shorter sides I fastened, by a few stitches of sewing cotton, a short piece of glass tubing. On to one of these pieces I adjusted a long piece of rubber tubing. I placed the apparatus in a tank, bringing the tubing out over the edge of the glass front, and allowing it to act as a siphon, drawing water out of the tank. While the siphon was running I placed the india-rubber flap gently against the glass inside the tank under water, and it remained adhering to the surface. The front piece of glass tube now represented the respiratory channel of the fish, and above and below it were apertures between the front of the tank and the rubber flap, representing the apertures above and below the snout in the case of the fish. The action of the siphon represented the pumping action of the muscles and fins in the fish. There was nothing in the model to represent the respiratory movements of the fish, but that does not invalidate the comparison. When the siphon was stopped by pinching the rubber tubing outside the tank, the rubber flap fell away from the glass and sank slowly to the bottom of the tank. I think with this confirmation the evidence I have now given in support of my explanation of the adhesion of the fish to vertical surfaces is amply sufficient. I have observed that when other kinds of flat-fish cling to the vertical surface of the glass front of an aquarium they move the posterior parts of the unpaired fins in the same way as Zeugopterus, but these parts of the fins and the muscles adjacent being less developed, the action is neither so powerful nor so long maintained.

There can be little doubt that the explanation above given applies to $Z$. unimaculatus, in which the habit of adhesion was observed by Brook, as well as to $Z$. punctatus. It probably applies also to $Z$. norvegicus, but I have not yet ascertained whether this species has the same habit. We do not know at present whether there are any other important differences in mode of life between Zeugopterus and other genera,-such, for instance, as kind of food. We know that these flat fishes are not entirely confined to rocks, but are also found on sandy bottoms with other flat fishes. There is no doubt that when adhering to a rock, one of these fishes accommodating 
its colour to that of the rock surface is well concealed from observation, and in this way its habit is an advantage to it, just as the habit of covering itself with sand is of advantage to a sole. But according to the present state of our knowledge the only generic character which is necessary to the peculiar habit is the great development of the posterior muscles and fins, which is the chief factor in the characteristic shape of the body. It is possible that the roughness of the upper surface, due to the spines of the scales, adds to the concealment of the fish by aiding in the resemblance to a rock surface. But no use has yet been found for the subcaudal prolongations of the fins or the perforation of the gillseptum.

With regard to the specific characters, nothing is known of peculiarities in mode of life which would give an importance in the struggle for existence to the concrescence of the pelvic fins with the ventral in punctatus, to the absence of this character and the elongation of the first dorsal ray in unimaculatus, or to the absence of both characters in norvegicus. No use is known, in fact, for any of the other specific characters, of which a brief review may be here given. The characters tend to form a series. Thus, in size, norvegicus is smallest, unimaculatus larger, and punctatus largest, the last reaching a length of $8 \frac{1}{2}$ inches. The subcaudal fin-flaps are least developed in norvegicus; most in punctatus; each has four rays in norvegicus and unimaculatus, six in punctatus. The shortening and spinulation of the scales are greatest in punctatus, least in norvegicus. In punctatus there are teeth on the vomer, in unimaculatus none, in norvegicus they are very small.

According to the studies of Jordan and Goss, the flat fishes form three well-marked sub-families, including the most numerous and important forms, and sundry other sub-families of less importance. These three are those whose familiar British representatives are the turbot, the plaice, and the sole; they may be called the Rhombinæ, Pleuronectinæ, and Soleinæ. I do not follow the American authors in their application of the names. The Rhombinæ have the following principal distinguishing characteristics.

The body is sinistral. The mouth is symmetrical, the dentition nearly equally developed on both sides, and the teeth acute. Pectorals and pelvics usually well developed, and the pelvics asymmetrical, that of the left or eyed side inserted on the extreme edge of the abdomen, its rays more or less wide apart; that of the right side inserted on the right side. Caudal fin rounded or subtruncate. Vertebræ in moderate or small number. Species chiefly tropical or subtropical.

It is to this division that Zeugopterus belongs. The nearest 
relative of Zeugopterus is certainly the megrim, which has the perforation in the gill-septum. This fish was united with Zeugopterus by Steenstrup, with Arnoglossus by Day. Günther places it as a sub-genus of Rhombus, with the name Lepidorhombus, and in my opinion it is best to separate it altogether under this name. The only other species of the genus is Lepidorhombus Boscii. I do not know whether the latter has a perforated gill-septum, but think it probable. The chief characters of Lepidorhombus are the very large mouth, thin body, and skin with little pigment and ciliated deciduous scales. Citharus linguatula, Günther, closely resembles the megrim, but has unequal teeth, and is destitute of the perforation of the gill-septum. Arnoglossus is a fairly well-marked genus, of which several species have been described, but only two (laterna and Grohmanni) are definitely known to myself. The scales are small and feebly ciliated, very deciduous, the skin also being very thin and weak, so that it is easily torn and detached. The mouth is comparatively small, much smaller than in Lepidorhombus. The fish are of somewhat small size. The presence of secondary sexual characters must be regarded as characteristic of this genus, some of the anterior median fin-rays being elongated in the male. All these forms are confined to the coast of Europe. Two species from deep water in the Gulf of Mexico have been assigned to Arnoglossus, but there is little probability that they rightly belong to it.

Rhombus is a genus which is distinct from all those above mentioned. It has a broad, usually strong body, with a thick skin; a broad interorbital area, whereas in the preceding forms it is narrow, and scales small, cycloid, or wanting. The mouth is large and the jaws strong; the teeth small, in bands, and nearly equal. The specific differences consist chiefly in the character of the dermal armature. In the brill (Rhombus lævis) the scales are cycloid and imbricate on both sides of the body, and there are no bony tubercles; the anterior rays of the dorsal are somewhat prolonged and much branched. In the turbot (Rhombus maximus) there are no scales, but bony tubercles scattered over the upper surface, absent on the lower; and the anterior dorsal rays are not prolonged, or distinguished in any way. These two are confined to Europe; on the American coast of the Atlantic there is a species resembling the brill called $R$. maculatus, known commonly as the window-pane, from its thinness. It is scaled on both sides, and the anterior rays are more prolonged than in the European brill. Transitional forms between the brill and the turbot have long been known, and were originally described as a separate species under the name $R$. mooticus by Pallas in Zoogr. Ross. As. in 1811. Specimens from the Black Sea have been frequently described since, and they seem to be more 
abundant there than elsewhere. Steindachner (Ichth. Berichte, 1868) states that a complete series of gradations between the ordinary turbot, in which the scales are obsolete, and the scaly turbot, which is more or less completely scaly, is to be observed. $\mathrm{He}$ obtained one of the most completely scaled specimens from the Baltic. Whether these specimens are to be regarded as variations, a variety, or as hybrids, we do not know. If they breed true, so that a scaled specimen is derived from scaly parents, then they form a variety, but this seems unlikely; it seems more probable that scaled forms occasionally develop from ordinary parents.

Another interesting genus in the Rhombinæ closely allied to Rhombus is Rhomboidichthys, called Platophrys by Jordan and Goss. In this genus the scales are small and ctenoid, and not deciduous. The interorbital space is very broad, and the peculiar position of the dorsal eye gives a curious appearance to the fish. There is a slight difference between the sexes, the pectoral of the left or upper side being filamentous in the male. Many species have been described from the West Indies and east coast of South America, and one from the Pacific coast.

It is unnecessary at present to refer to any of the remaining genera or species of the Rhombinæ which are less known. The principal characters by which the best known forms are distinguished have been mentioned, and what do we know of the functions of those characters? No one has hitherto been able to suggest a reason why the scales are more useful to the brill and tubercles to the turbot. We do not know why the male Arnoglossus requires elongated finrays, a kind of piscine moustache, a masculine ornament which is developed in several other species of fish. We can say with truth that the Rhombinæ are for the most part predaceous flat fishes which seize active prey, and to this habit of life the large symmetrically developed mouth and teeth are adapted. It is quite possible, too, that if we knew the habits of particular species more exactly and more completely, we should see that the whole muscular system and shape of body, as well as the particular size of mouth, were adapted to the particular habits and surroundings. But this leaves some of the features most important in diagnosis, such as the scales and the secondary sexual characters, unexplained.

A different set of characters offering similar difficulties occurs in the sub-family Pleuronectinæ. The common features of this subfamily as diagnosed by Jordan and Goss are the following:

Mouth small, asymmetrical, the jaws on the eyed side with nearly straight outline, the bones on the blind side strongly curved; dentition chiefly developed on the blind side; eyes large; edge of pre-opercular not hidden by the scales; pectoral fins well developed; 
unpaired fins well separated; pelvic fins nearly or quite symmetrical ; body dextral. Species arctic or subarctic in distribution.

In this sub-family Jordan and Goss make our common dab the type of a genus. The characters are-

No accessory branch to the lateral line, but a distinct arch in it over the pectoral.

Scales rough, ctenoid, and imbricated.

Vertebræ forty in number.

The authors recognise four species. One of these is doubtful, founded by Prof. Goode on certain specimens taken in deep water off the southern coast of New England. Limanda limanda, the European form, has no rugose prominences above the operculum behind the interorbital ridge. The fin-rays are-dorsal 65 to 78, ventral 50 to 62 ; scales along the lateral line 86 to 96 , teeth in an irregular series. This species extends from the Atlantic coasts of France along all the coasts of Northern Europe, and on the coast of Iceland: it is absent from the Mediterranean.

Limanda ferruginea is the dab of the American side of the Atlantic, extending from New York to Labrador. It differs from ours in having more numerous teeth in a more regular close-set series, a more projecting snout, and rugose prominences above the operculum. The fin-rays are a little more numerous, namely, D. 85, A. 62. The scales are smaller and more numerous, namely, lateral line 100 .

Limanda aspera is the dab of the North Pacific. It is distinguished by somewhat marked characters, of which the principal are that there is no angle between the snout and the profile of the head, and the scales of the blind side are more or less rough, those of the upper side rougher than in the other species. Specimens have been taken on the coasts of both Alaska and Kamtschatka. It seems, therefore, that while the species on opposite sides of the Atlantic are different, those on opposite sides of the Pacific are the same. This case offers an instance of geographical races. The differences are not great, but if they are constant it matters little whether we call these forms, species or varieties or races. The case affords a contrast to that of Zeugopterus; in the latter we have three species in the same area, separated by no barriers except those which are physiological : in other words, they do not interbreed. In the case of the three forms of Limanda interbreeding is physically impossible, except where the ranges meet. We have no evidence that the differences are adaptational.

Closely allied to Limanda is a species in the Pacific called by Jordan and Goss Lepidopsetta bilineata. Only one species is placed in the genus, the establishment of which seems superfluous. The 
form is distinguished from Limanda by the presence of an accessory branch of the lateral line, which starts from the anterior portion of that line, extending in all members of the family above the eyes, and runs backward along the base of the dorsal fin. It is a curious fact that this variation is known as a constant character only in the Pacific, and that there it occurs in a large number of species : of the thirteen species of this sub-family in that ocean distinguished by Jordan and Goss it occurs in eight; and it also occurs in one genus, also in the Pacific, in the quite distinct sub-family Hippoglossinæ. A fact of this kind cannot be explained simply as an adaptation; it cannot be supposed that there is some common peculiarity in the habits and surroundings of all these species which renders this particular extension of the lateral line useful.

The plaice (Pleuronectes platessa) is distinguished from $P$. limanda by wanting the arch to the lateral line, having cycloid reduced scales and tubercles on the post-ocular ridge. The flounder has differentiated scales, most of them being reduced and cycloid as in the plaice, but those along the bases of the longitudinal fins, along the lateral line, and on the head being enlarged to form rough spiny tubercles. Pseudo-pleuronectes americanus, the representative of the plaice on the east coast of America, approaches the dab in having imbricated ctenoid scales. In Liopsetta Putnami the spinulation of the scales is a sexual character, the scales in the male being rough and strongly ctenoid, in the female smooth and almost completely cycloid. This species ranges from Cape Cod to Labrador. Mr. Holt, in the last number of the Journal, has described specimens of the plaice from the Baltic in which ciliation or spinulation of the scales, although varying in different individuals, was distinctly a sexual character more strongly developed in the males. Möbius, in his Fishes of the Baltic,* mentions these ciliated plaice, and observes that they form a transition to unusually smooth specimens of the flounder. The smooth flounders, although occurring on the south coast of England, are stated to be commonest in the Mediterranean, where they seem to occur exclusively. It appears, therefore, that there is a northern rough variety of the plaice and a smooth variety of the flounder in the south.

We have at present no evidence that these differences are adaptational, nor can we trace them to preceding or determining causes. But, on the other hand, we must admit adaptation in many of the characters of the sub-family. For instance, the small size and asymmetrical shape of the mouth correspond to the general habit of these fish of feeding on invertebrate slow-moving creatures on the sea bottom. The fish seize their prey from above with the lower side of the

* IVte Bericht der Comm, zur Unters. der Deutschen Meere, 
jaws. But many of the characters of the sub-family cannot definitely be proved to be adaptive, e.g. the narrow symmetrical pelvic fins and the slight anterior extension of the dorsal fin.

\section{The Development of the Egg in Flat Fishes and Pipe-fishes.}

Since my paper in Vol. III, No. 2, p. 154, of this Journal was written I have been continuing my studies of the development of the eggs in the ovaries of fishes. My attention has been given principally to the history of a definite body in the yolk known as the vitelline nucleus, but quite distinct from the proper nucleus of the egg or germinal vesicle. I hope to be able at some future time to publish a full account of my observations with adequate illustration, but in the meantime some account of the subject in the Journal of the Association may be useful.

In the fresh state it is almost impossible to perceive any trace of the vitelline nucleus, only a faint indication of it can be made out after familiarity with it has been gained by the study of its structure in preparations which have been subjected to the action of reagents. In fishes in which the eggs before the development of yolk are extremely transparent the structure can be easily seen after treatment with dilute acetic acid, in a small portion of the ovary simply spread out on a slide. In those eggs in which the development of yolk has made considerable progress the body in question can only be seen in prepared sections. In a piece of the ovary of a flat-fish in which there is no yolk-for instance, a flounder or plaice, - on the addition of acetic acid the transparent protoplasm of the egg gradually coagulates, and the first change to occur is the appearance of the vitelline body as a spot which is more opaque than the surrounding substance. In the larger ova (Fig. 1,b) this body is round and of considerable size, somewhat larger than one of the nucleoli of the germinal vesicle, and it is situated between the germinal vesicle and the surface of the ovum. Examined with a high power it is seen to consist of a spherical collection of minute granules. In the smaller eggs (Fig. 1,a) those about $\cdot 118$ $\mathrm{mm}$. in diameter, the vitelline nucleus is somewhat smaller and close to the surface of the germinal vesicle. In still smaller eggs, only $\cdot 10 \mathrm{~mm}$. in diameter, the body can just be discerned as a few granules just outside the membrane of the germinal vesicle, and in ova smaller than this no trace of it is visible, I have not been able to see any indication that the vitelline body is situated on a particular side of the egg. The egg is approximately spherical; the 
question whether the radius of the sphere which is determined by the presence of the vitelline body has any particular position in the subsequent history of the egg will be considered later.

It will appear, then, that the body in question, judging from examination of entire fresh ova treated with acetic acid, is not present in the youngest ova, but becomes visible when they have reached a

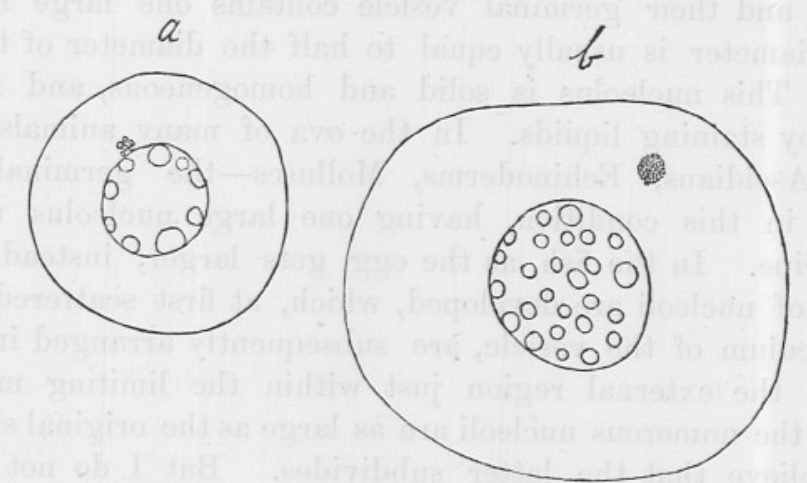

FIG. 1.-Developing eggs from the ovary of a plaice $8 \frac{3}{4}$ inches long, examined August 30th, 1894 ; treated with dilute acetic acid. Seen with Zeiss E, oc. 3.

certain definite size; that it makes its appearance in the form of a few granules close to the wall of the germinal vesicle, and as the egg becomes larger is gradually more and more separated from the latter, at the same time increasing in size and opacity. 'This suggests that the body is formed from the germinal vesicle by the expulsion of granules; but no direct evidence of this can be seen, and, moreover, it is not supported by the fact that the vitelline body increases in size after it is separated by a layer of protoplasm from the germinal vesicle. In eggs in which the yolk has begun to appear at the surface of the cell-plasma the vitelline body is seen beneath the layer of yolk granules, and it never actually reaches the surface of the egg.

After the character of the vitelline body has been studied in ova treated with acetic acid, it is possible sometimes to make it out in living ova without the addition of any reagent. It is seen then as a group of faint granules whose opacity and refringent power are very slightly different from those of the surrounding cell-plasma.

There is, therefore, a stage in the development of the ova in a flat-fish in which neither the vitelline nucleus nor the yolk have appeared or commenced to develop. It would be interesting to have a satisfactory account of the whole history of the ovum, and particularly of this early stage, but at present there are many passages in the history not yet elucidated. In prepared sections of an 
ovary from an immature fish-for instance, a plaice $7 \frac{1}{2}$ inches long killed in March-the youngest ova are seen beneath the surface of the germinal lamellæ. The lamellæ are covered by a very thin membrane containing nuclei. This membrane represents what is known as the germinal epithelium, but it is so thin that it is difficult to see much of it in transverse sections. The smallest ova are rounded, and their germinal vesicle contains one large nucleolus, whose diameter is usually equal to half the diameter of the whole vesicle. This nucleolus is solid and homogeneous, and is darkly stained by staining liquids. In the ova of many animals-for example, Ascidians, Echinoderms, Molluscs-the germinal vesicle remains in this condition, having one large nucleolus until the egg is ripe. In the fish, as the egg gets larger, instead of one a number of nucleoli are developed, which, at first scattered through the reticulum of the vesicle, are subsequently arranged in a single layer in the external region just within the limiting membrane. None of the numerous nucleoli are as large as the original single one, and I believe that the latter subdivides. But I do not think all the new nucleoli are produced by subdivision of the original one, because in the younger and smaller ova there are to be seen very minute nucleolar granules together with a large undiminished nucleolus, so that it is to be inferred that many of the additional nucleoli are produced by the increase in size of these minute granules.

In very young fish none of the ova contain a vitelline nucleus; for instance, in sections from a plaice 3 inches long, killed in March and probably a year old, it is not to be seen. In these sections the largest ova have a diameter of $\cdot 07 \mathrm{~mm}$. The production of young ova in this ovary was evidently going on rapidly; nests of them are present at numerous spots in contact with the germinal epithelium. But even at this early stage nuclear division figures are not to be seen, nor have I detected such figures in sections of the ovary at any stage. It may be that even in the young ovary the youngest ova seen have passed beyond the division stage and entered upon the period of growth, and that division only takes place in the flat germ-cells of the epithelium, and cannot be seen in sections. But even when examining the germinal epithelium from the surface I have seen no division figures, nor am I aware that other observers have described any. It is a point which requires further investigation.

In sections from a plaice $7 \frac{1}{2}$ inches long, fixed with chromic and osmic acids, the vitelline nucleus is distinctly visible in the larger ova, whose diameter has a maximum of $14 \mathrm{~mm}$. The appearance of the nucleus is quite different from that of the nucleoli in the germinal vesicle; its outline is not so definite, and it is seen to be a 
group of refringent granules. It does not stain so deeply as the nucleoli. The younger stages of it described above as seen in fresh preparations are not visible in the sections, but only the later stages in which it is situated near the surface of the ovum.

The vitelline nucleus persists in the ovum during the development of the yolk. To obtain satisfactory sections of the yolked ova, as a rule other reagents must be used than those which succeed best with the ovaries in which yolk has not begun to develop. Picrosulphuric acid is one of the reagents which give good results. I have some sections prepared with this reagent from a large plaice taken from the aquarium and killed in August. In these many of the smaller yolkless ova are collapsed and shrunken, and the connective tissue between the ova is distended and broken, but the yolked ova are in many cases wonderfully perfect. The stain used was hæmatoxylin, and the yolkless ova are over-stained, but in this respect also the yolked ova are very satisfactory. The yolk forms an external layer of varying thickness according to the size of the egg; and between it and the germinal vesicle is a layer of finely reticulate protoplasm. The vitelline nucleus has a shape which suggests that of an octopus: towards the centre of the egg it is rounded and has a definite outline, although it is not separate from the surrounding protoplasm, but continuous with it. It lies on the inner boundary of the layer of yolk, which consists of small yolk spherules. On the outer side the vitelline nucleus gives off a number of diverging processes which run into the yolk layer, becoming continuous with the protoplasmic strands which separate and enclose the yolk spherules. The substance of the vitelline nucleus is deeply stained (in hæmatoxylin), and in structure is finely granular, not as in the younger stage composed of a small number of refringent granules.

As the thickness of the yolk layer increases it at lasts passes the vitelline nucleus, so that the latter comes to be situated entirely within the yolk-containing layer of the egg, and can be seen as an island of granular protoplasm surrounded by the yolk spherules. In this condition it is not so conspicuous, and is relatively smaller. My preparations showing this stage are from a large plaice killed in August, and the largest eggs in the sections are about $28 \mathrm{~mm}$. in diameter. In these most advanced eggs there is still a layer of protoplasm containing no yolk between the layer of yolk and the germinal vesicle.

During the development of the yolk the germinal vesicle exhibits changes. The chief of these is that the nucleoli are no longer almost always arranged in a single row at the outside of the vesicle, but are seen scattered in the central regions. In many preparations 
the membrane or outline of the germinal vesicle is much wrinkled and contracted, but this is to a certain extent due to the action of reagents. It occurs in preparations made with corrosive sublimate and acetic, and with picro-sulphuric acid, but in some preparations made with chrom-osmic acid it is less marked. On the other hand, in a piece of the ovary from a flat fish just killed and placed on a slide beneath the microscope, without the addition of water or any reagent, the wrinkling of the membrane of the germinal vesicle is very frequently observed in the larger transparent ova and in those in which yolk is commencing to develop. It is probable enough, therefore, that this wrinkling of the membrane is, to some extent, a natural phenomenon occurring during life, although there can be no doubt that in many preparations the nucleus has been further altered and contracted by the action of the reagents.

This wrinkling of the membrane is the same condition which is described by Scharff * as the formation of peculiar protuberances all over the outer surface of the germinal vesicle in eggs of the gurnard. His fig. 9 agrees closely with the appearance presented in many of my own preparations. But he gives an extraordinary interpretation of the changes taking place, which I am quite unable to accept.

He states that the protuberances containing nucleoli are separated off, carried towards the exterior of the egg, and there form the yolk spherules, having the appearance of cells containing a nucleus. I am unable to trace any direct connection between nucleoli and yolk spherules. I have failed to find after long and careful scrutiny the slightest evidence that the nucleoli migrate at all. It is true that occasionally a nucleolus in a prepared section appears to be outside the nuclear membrane, but I find this is always due to one or other of two causes; either the nucleolus has been bodily pushed out of its place by the edge of the razor which failed to cut through it immediately, or the pouch of the wrinkled membrane has been cut in such a manner in the section that it is separate from the interior of the main germinal vesicle. In the latter case the connection can be seen in the next section. In the former case the artificial nature of the occurrence is easily proved by observing that the direction in which the nucleolus has moved is the same as that of other striæ in the section caused by the razor. The nucleoli become very hard after the action of chromic acid, and it is in preparations from tissue hardened with this reagent that such dislocations usually occur. The hypothesis that the nucleoli give rise to the yolk spherules is untenable from the nature of the case, for the spherules are very numerous, and as the egg ripens form a bulk

* Quarterly Journal Micr. Sci., vol. xxviii. 
many times greater than the germinal vesicle, or than all the nucleoli put together. There is no indication of a rapid formation of nucleoli, and at the end in the egg almost ripe there are still a number of nucleoli remaining. It is practically certain, therefore, that the yolk spherules are formed in situ, first on the outside of the egg and then progressively inwards.

Another point in which I am unable to agree with Scharff's description is his account of the division of the protoplasm of the egg into two layers. In this case again, in my opinion, he has been misled, as many others have been in microscopical researches, by alterations due to method of preparation and the action of reagents. Scharff states that the ovaries from which his sections were prepared were hardened with weak chromic or with picro-sulphuric acid, both excellent reagents which I have largely used myself. But he states that his preserved material was prepared not by himself, but by Professor McIntosh; and it is not certain whether the ovaries were perfectly fresh when preserved-a very important point. My experience is that when preparations are made from fish obtained in the market which have been dead several hours, the preserving liquid used being Perenyi's mixture, a division of the protoplasm into two zones is seen. The ovary when examined fresh appears perfectly unaltered, but after preparation produces a result different from that obtained from an ovary taken from a fish just killed. The outer lighter zone is frequently separated from the inner. In all my successful preparations from ovaries preserved immediately after the death of the fish there is no division of the protoplasm into zones in the yolkless ova, and in the older ova the only distinction is that between the outer layer containing yolk granules or spherules, and the inner layer where there is no yolk. In young yolkless ova, whether in sections from immature ovaries in which all the ova are in this condition, or in sections from ovaries in which the majority of ova are larger and developing yolk, the whole of the protoplasm is deeply stained, almost as deeply as the nucleoli, while the rest of the germinal vesicle is scarcely stained at all. In fact, the protoplasm of the ovum from its earliest appearance is distinguished by its affinity for stains, which causes young ova to contrast vividly with the connective tissue of the sections. The staining is less after the action of chromic acid, but after corrosive sublimate or picro-sulphuric acid it is usually intense. Yolk substance, on the other hand, does not stain at all, and hence in older eggs the contrast between the unstained yolk layer and the inner protoplasmic layer is marked. In the older eggs, however, the inner unyolked protoplasm does not stain so intensely as the protoplasm of the young unyolked eggs. In some preparations the protoplasm of NEW SERIES.—VOL. III, NO. IV. 
the unyolked ova is much vacuolated; this occurs only when some preserving agent containing much nitric acid has been used, such as Perenyi's mixture or picro-nitric acid, and is due to the action of the nitric acid.

Several investigators have expressed the conclusion that the vitelline nucleus is connected with the formation of the yolk,-is the centre, in fact, at which this process takes place. This is a suggestion which one would be glad to accept if possible, because it would afford a satisfactory explanation of the presence of this body, otherwise so difficult to understand. A very interesting and useful examination of the problem from this point of view is contained in the account given by Professor Emery of the history of the egg of Fierasfer in his monograph on that genus published by the Zoological Station of Naples. In many respects I find Professor Emery's observations and views much more in agreement with my own than those of other authors who have considered the development of the egg in fishes. In my judgment he shows a sounder and more comprehensive grasp of the succession of appearances to be interpreted, and has no inclination, like many others, to form extraordinary conclusions inconsistent with the general view of the nature of the egg, and supported by scarcely any evidence.

Emery's description of the earlier history of the vitelline nucleus agrees, to a great extent, with mine. It appears, he says, as a small mass of granulations excentrically situated, and then becomes larger and denser, but never acquires a definite boundary. Its ultimate history consists in its gradual disintegration with the formation of the vitelline spherules. The granular vitelline nucleus assumes an irregular form, more or less stellate, and often shows in its interior one or two small clear vacuoles. Around the nucleus extends an obscure zone, semilunar in section, of very minute granules, the beginning of the formation of the vitelline globules. This zone continually extends and surrounds the whole ovum, and as the yolk-globules get larger the vitelline nucleus becomes merely a small clear space in the layer of formed yolk. Emery goes on to say that it is not clear from these facts whether the yolk-globules are formed exclusively at the expense of the vitelline nucleus, or in part from this and in part directly from the plasma of the ovum, or if, lastly, the vitelline nucleus is formed and disappears without its substance contributing to the production of the yolk.

Emery, then, was not able to decide in what way the vitelline nucleus is connected with the formation of the yolk-globules, but he states that the development of these globules commences in Fierasfer in the immediate neighbourhood of the nucleus and extends outwards. It should be noted that the eggs of Fierasfer are, when mature, 
transparent and pelagic like these I have studied. I have been unable to find any indication that the yolk commences first in the neighbourhood of the vitelline nucleus. As I have already stated, the yolk layer is at first wholly external to the nucleus, and there are no yolk-globules or granules at the side of the latter. When the formation of granules begins it appears as a thin layer round the whole of the outside of the plasm of the egg, and is not thicker near the vitelline nucleus than elsewhere. In most ova the layer of yolk in sections is of uniform thickness, but occasionally it is thicker on one side than the other, and then the vitelline nucleus is not at the thickest part. In spite of the fact that the largest yolk-globules are those of the inner part of the yolk layer, it seems certain that the increase of yolk takes place by the new formation of globules added to the layer on the inner side. Forming globules are seen at the inner edge of the layer. After the yolk layer has so increased that its inner border is internal to the vitelline nucleus, it is clear that the new formation of globules can have nothing to do with that body.

The most recent published paper on the yolk nucleus is that by Jesse W. Hubbard, of Indiana University, U.S.A.* This investigator studied the eggs of Cymatogaster aggregatus, a viviparous fish of the coast of California, and his conclusions closely agree with my own. Cymatogaster belongs to the family Embiotocidæ, which is allied to the wrasses. The eggs of Cymatogaster are small, $\cdot 3 \mathrm{~mm}$. in diameter, and being developed within the ovary the quantity of yolk in them is naturally small. The preserving reagent used by Hubbard was Flemming's strong mixture, the effects of which I have found in my own experience to be destructive to many parts of the egg. Like myself, Hubbard could see no trace of the yolk nucleus in very young fish, in those under $4 \mathrm{~cm}$. in length. It was present in the ovaries of specimens over $7 \mathrm{~cm}$. The smallest egg in which the body was observed was $02 \mathrm{~mm}$. in diameter, and it appeared as a cap of stained protoplasm fitting round one side of the nucleus.

In a slightly larger egg the yolk nucleus is separate from the germinal vesicle, and it gradually moves away from the latter. Hubbard concludes that the yolk nucleus originates from the germinal vesicle not by division, but by a general extrusion of substance. It passes to the external region of the egg, and when the yolk is formed and the egg is ripe it is situated at the yolk pole of the egg, opposite the blastodisc. It remains visible in the same position in the yolk after the egg is laid, and during segmentation until the closing of the blastopore, when it breaks

* The Yolk Nucleus in Cymatogaster aggregatus, Proc. Amer. Philos. Soc., vol. xxxiii, 1894. 
up and disappears. Hubbard considers that there is no direct evidence in support of the view that the yolk nucleus is the centre of yolk formation; he has seen no indication that it gives rise to yolk. When the yolk forms it is distributed uniformly about the centre of the egg. Perhaps Hubbard's most important result is that the yolk nucleus passes to the opposite pole of the egg to that occupied by the germinal vesicle, and so defines the yolk pole, or, as it is sometimes called, the vegetative pole, long before the germinal vesicle has passed to the surface of the egg from the central region. I have not yet examined the last stages of maturation of the eggs of flat fishes. I have never detected the yolk nucleus in the eggs of these fishes after fertilization, when, if it is to be seen at all, it would be found in the thin layer of protoplasm which encloses the continuous mass of yolk. In my sections of the ova of conger nearly ripe, taken from females which have died in our tanks with enlarged and much-developed ovaries, in which ova the yolk is fully developed, I have not been able to detect the yolk nucleus.

The wrinkling of the membrane of the germinal vesicle already mentioned is an indication of its degeneration. In the later stages of maturation, as the limit of the yolk layer approaches the germinal vesicle, the membrane gradually disappears, and the nucleoli become scattered in the reticulum of the vesicle. At the same time this reticulum appears to become denser, and although it still remains unstained it has a more solid continuous appearance. In eggs nearly ripe-for instance, in preparations from a plaice killed in January, in which some of the eggs were becoming transparent-the whole body of the ovum is crowded with large yolk spheres, and the germinal vesicle forms an unstained round island in the midst of these, containing a number of stained nucleoli. No membrane, separating the nucleus from the protoplasm in which the yolk spheres are contained, can be seen. The later changes by which the nucleus of the egg, and especially its nucleoli, pass from a central to an external position in the ripe egg when extruded I have not yet studied.

The description given shows the history of the ovum in a flat-fish from the time of its first origin in the germinal epithelium to the stage in which it is almost ready for extrusion. The history is probably almost exactly similar in all fishes which produce pelagic eggs and have an annual spawning season. As I pointed out in my previous paper, the great majority of the eggs pass through the whole of this history in the course of a year, between one spawning season and the next. I have made preparations from ovaries in which spawning had just taken place, spent ovaries, with the following results. 
In my previous paper I described the condition of the spent ovary of the plaice, as seen when microscopically examined in the fresh condition, and expressed the conclusion that all the unripe eggs containing yolk remaining in the ovary were destined to degenerate and be absorbed. The chief characteristic of sections of a spent ovary consists in the number of empty follicles seen. These are the collapsed receptacles in which the ripe ova were developed, and from which they have been expelled. The mode of expulsion is constant and of some importance. The follicle bursts at the surface of the germinal tissue, the egg therefore escaping through a rupture of the so-called germinal epithelium. When this takes place the wall of the follicle becomes continuous with the external covering of the germinal tissue,-that is to say, with the germinal epithelium and the connective tissue which supports it. Such an empty follicle corresponds with what is called a corpus luteum in the mammalian ovary. In the fish its walls are thick, and contain many blood-vessels : it may be regarded as an elastic membrane, which, having been stretched round the large ripe egg, becomes thickened and contracted when the latter escapes. In the cavity of the follicle are always seen the separated and broken follicular cells, but there are indications of cells on the surface of the interior of the follicle, so that perhaps not the whole of the follicular epithelium perishes. The appearance of the empty follicles, opening by an aperture at the surface of the germinal tissue, and of their walls, continuous with the membrane at the surface, strongly suggests the idea that a follicle is simply a pocket formed in the germinal membrane and temporarily constricted off from it, being restored to it again when the mature egg is expelled. But whether the wall of the follicle becomes again a part of the germinal membrane and begins again to produce new ova, or whether it is gradually absorbed, is a question I am unable to answer at present. In the larger of the young yolkless ova in the spent ovary the vitelline nucleus is present.

I have now to describe some observations on ovaries in which the history of the ova presents considerable differences from that which is characteristic of flat fishes and other fishes with pelagic ova.

Henneguy,* in a recent paper on the vitelline nucleus, states that among all the Teleosteans whose ova he examined, those of the pipefish (Syngnathus acus) gave him the most interesting facts. These facts are described thus:-There are four stages of the development of the vitelline body: (1) The smallest ova have no vitelline

* Le corps vitellin de Balbiani dans l'ceuf des Vertébrés, Journ. de l'Anat. et de la Physiol., No. 1, 1893. 
body; (2) in ova more advanced than the youngest the germinal vesicle has a number of nucleoli round its circumference within the membrane, and a granular mass in the centre; the protoplasm of the ovum contains a round refringent body deeply stained in safranin, the vitelline nucleus; (3) in ova about $.06 \mathrm{~mm}$. in diameter the vitelline nucleus has become elliptical in shape, and at its outer border is a larger rounded mass formed of a homogeneous substance full of granulations; (4) the whole is transformed into a mass of granules, such as that observed in the ova of the majority of Teleosteans. The outer rounded body is described as formed by a modification of part of the refringent body, by a process of disintegration which finally invades the whole of the latter, and transforms it into a mass of granules. Unfortunately Henneguy omits to state what is the condition of the yolk corresponding to these stages, and the only indication of the size of the eggs is that in stage 3 they are $.06 \mathrm{~mm}$. in diameter.

My observations do not completely agree with Henneguy's, but before pointing out the differences I wish to say something of the ovary. This organ in the pipe-fish is an elongated narrow cylindrical tube. There is one on each side of the body. It has a salmonpink colour, due to the colour of the yolk in the eggs. The inner lining of the tube, the germinal tissue, only projects into the cavity of the tube in one fold or lamina, which is longitudinal. In this lamina alone are the young eggs formed, and they are pushed away from it as they become larger.

A long series of stages of the developing ova can thus be studied in a single ovary, and the production of new ova seems to go on nearly all the year round,-at least, I have not yet seen evidence of a limited spawning season, and specimens with ripe ova or just spent have been opened by me from June to October. I believe that several batches of ova are produced in one season in succession. The number of ova produced is small, and, as is well known, they are received by the male into a skin pouch, and there hatched.

It is not difficult to open the ovary and examine the proliferating lamina on a slide. In the fresh state the young yolkless ova are not very transparent, and it is impossible to make out any other structure than the germinal vesicle. But on the addition of dilute acetic acid the protoplasm of the eggs begins to coagulate, and in it there appears in most cases (Fig. 2) a single oval body, which in the smaller ova is in contact with the membrane of the germinal vesicle, in the larger is between it and the exterior of the egg. This body is of considerable size, both it and the nucleoli in the germinal vesicle being relatively larger than in the egg of the flatfish. Another peculiarity of this vitelline body is that it has a most 
distinct and definite outline, and a refringent homogeneous interior. Occasionally a few granulations appear in its centre. The body is not much unlike a nucleolus, but the nucleoli, under the action of acetic acid, show internal vesicles and the vitelline body does not; the latter has also a pale yellowish colour, while the nucleoli are colourless.

FrG. 2.

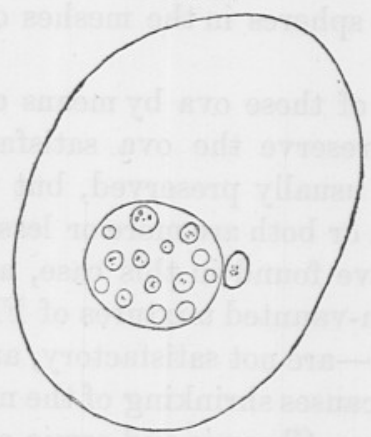

FIG. 3.

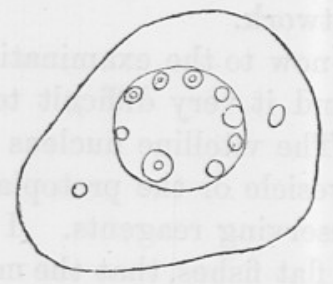

FIG. 2.-Egg in the germinal ridge of Syngnathus acus examined fresh with addition of 1 per cent. acetic acid. Shows the vitelline body close to the germinal vesicle.

FIG. 3.-Another egg in the same preparation, showing two vitelline bodies on opposite sides of the germinal vesicle.

The most remarkable fact about the vitelline nucleus in the ova of the pipe-fish is that there are often more than one of them in a single egg, frequently two, and I have seen as many as four. In the latter case the four were in a cluster, as though produced by the division of one, but when there are two they may be both on one side of the germinal vesicle, or one on one side and one on the other (Fig. 3). Henneguy examined the ovary of the pipe-fish apparently only in sections, and would not be so likely in that case to recognise the presence of two vitelline bodies in one ovum. The bodies can be well seen and studied in preparations of portions of the germinal lamella mounted whole. My best preparation of this kind was fixed in a mixture of chromic, osmic, and acetic acid, and stained with hæmatoxylin. The presence of two vitelline bodies in some ova in this preparation is easily confirmed. It should be noted that when two are present they are smaller in size than when there is only one. The structure certainly persists unchanged in ova in which yolk has begun to form. I have been able to distinguish it clearly in such ova of a diameter up to $29 \mathrm{~mm}$., and in these it is unchanged, showing no signs of the conversion into a granular mass which Henneguy describes as commenced in ova only $\cdot 06 \mathrm{~mm}$. in diameter. The vitelline nucleus is entirely unstained and homogeneous, and has an appearance very different from that of the nucleoli, which are somewhat shrunken, 
and are stained. In ova larger than $\cdot 3 \mathrm{~mm}$. I am unable to distinguish the vitelline nucleus in the yolk. The latter forms in the eggs of Syngnathus in a manner different from that described in the plaice. It does not form a definite external layer gradually thickening towards the centre of the ovum, but appears uniformly throughout the protoplasm in small, not very distinct or refringent granules, which increase in number and size. In the larger ova the yolk appears as large rounded spheres in the meshes of a protoplasmic network.

To turn now to the examination of these ova by means of sections. I have found it very difficult to preserve the ova satisfactorily for cutting. The vitelline nucleus is usually preserved, but either the germinal vesicle or the protoplasm or both are more or less destroyed by the preserving reagents. I have found in this case, as with the ovaries of flat fishes, that the much-vaunted mixtures of Flemmingnamely, chromic, osmic, and acetic-are not satisfactory, and that the fault lies in the acetic acid, which causes shrinking of the nucleus and destruction of its delicate reticulum. Chromic and osmic alone, when the chromic is not too strong, have a good effect, but have the disadvantages of contracting the nucleoli, preventing staining, and making the yolk hard and brittle. Corrosive sublimate, either alone or with acetic acid, produces quite disappointing results on the ovaries of pipe-fishes.

In none of my sections have I seen the modifications of the vitelline nucleus described by Henneguy, although I have used the preserving reagents and stains which he employed, namely, Flemming's mixture and safranin or hæmatoxylin. I have also used the triple stain safranin, gentian violet, and orange G. After some modes of treatment the vitelline nucleus is stained, but never granular. The largest egg in which I have seen the body is $.36 \mathrm{~mm}$. in diameter, and in this it is as definite in outline and as simple in structure as in the small unyolked ova. I have seen no indication of modifications tending to the breaking up or disappearance of the nucleus; in the larger eggs I can find no trace of it. As to its earlier history, it is seen in eggs $.06 \mathrm{~mm}$. in diameter in direct contact with the exterior of the germinal vesicle. In one egg there are two of these bodies at different parts of the membrane of the vesicle, one smaller than the other. In smaller eggs I have seen no trace of it. These smaller eggs form a cluster or nest at the very apex of the germinal lamella. As to their origin, I have not been able to get sections which show them as perfectly as I should wish, but I have seen primordial ova in the epithelium covering the apex of the lamella, and that is the source from which they all spring. 


\section{A Piebald Plaice.}

In the memoir by Dr. MacMunn and myself on the Coloration of Fishes (Phil. Trans., 1894) specimens of flat fishes are described in which some portion of the upper side is abnormally destitute of pigment. Thus abnormalities consisting in the pigmentation of part or whole of the lower side are balanced by abnormalities consisting in the absence of pigment from areas on the upper side. I have recently received a living specimen of the plaice exhibiting the latter kind of abnormality. It was caught in the Hamoaze, and brought to the Laboratory on October 3rd. It is still living in one of the tanks. The anterior third and the caudal third of the upper or right side in this specimen are pigmented as in a normal plaice, the red spots having the usual appearance and position; but the middle third is white like the whole of the lower side. The white unpigmented area is bounded by two definite irregular lines, the anterior passing transversely across the body just behind the pectoral fin, the other in the posterior region of the body. There is an isolated round patch of normal pigment within the white area dorsally.

Mr. Holt, in the previous number of this Journal (p. 188, et seq.), gives reasons why my rejection of atavism as an explanation of the abnormal coloration of the lower side cannot be held to be valid. But I can see no reason why the principle which explains the occurrence of pigment on the lower side should not also explain its occasional absence on the upper. If it is atavism in the one case it is atavism in the other, and the occurrence of piebald plaice, or flat fishes white on both sides, is as good an indication that this family of fishes is descended from ancestors that were unpigmented on both sides, as the occasional presence of pigment on the lower side that they are descended from ancestors coloured on both sides. Thus it is obvious that atavism fails to explain both kinds of abnormality, whereas the explanation adopted by Mr. Bateson and myself applies equally well to either case. That explanation is that in certain cases one side, instead of developing normally, partially or completely imitates the other. It does not require much consideration to see that Mr. Holt's reference to what he terms ambi-ciliation, tends to support my views, and not his own. For it is difficult to connect the varying conditions of the dermal armature in different kinds of flat fishes with an original ancestral condition. If the ciliated scales of the brill are ancestral, then the tubercles of the turbot are new, and vice versa ; but when 
the lower side is pigmented, it is also provided with scales or tubercles like the upper, thus proving that the lower side has in the abnormal specimen formed itself after the pattern of the upper side, and not after the pattern of a remote ancestor. It has never been maintained, as Mr. Holt suggests, that this unusual development of dermal armature on pigmented lower sides has anything to do with the action of light; on the contrary, I have always maintained that abnormalities of coloration occurring in nature are independent of the action of light on the individual.

The subject is too complicated to be discussed at any length here, belonging as it does to the intricate problems of ontogeny. But one interesting consideration may be mentioned. In a piebald plaice, such as the specimen here recorded, the unpigmented area is exposed to light as much as the rest of the upper side, and yet it remains unpigmented. How then, it may be asked, can it be maintained that pigment is developed on the lower side of a normal specimen by exposing that side to the light? Some may be inclined to believe that the two things are incompatible, and that therefore the pigment which appeared in my experiments is due to some factor other than the action of light. But it seems to me that, as far as the experiments are concerned, all other factors were excluded; and the explanation in the other case seems to be as follows:-I have said that the white area on the upper side is an imitation of the lower side, and I think that there is probably some peculiar connection between this area and the lower side, so that it may be regarded, in a sense, as an extension of, and continuation of, the skin of the lower side. Therefore, so long as the lower side remains white, this area of the upper side will also remain white. Possibly, if the lower side became pigmented, this white area on the upper side would also become pigmented, and it would be a curious experiment to expose the lower side to the light, and see if both it and the white area on the upper side would develop pigment.

\section{Growth and Distribution of Young Food-mishes.}

In April, 1893, I had the pleasure of undertaking some experiments with young flounders for the late Dr. Romanes. I procured the specimens as usual from Mr. Dunn, of Mevagissey. They were the young of the year in process of metamorphosis, and among them I received five young soles a little more advanced in development. I placed these five soles in one of the table tanks in the Laboratory, a tank 5 feet long, $2 \frac{1}{2}$ feet wide, $1 \frac{1}{2}$ feet deep. When received these soles were about $1.5 \mathrm{~cm}$. long, or nearly $\frac{5}{8}$ inch. 
During the following summer a number of young fish of different kinds were put into the same tank, and they have been fed and watched with some care ever since. The following is an account of their growth and history.

In June a few young turbot and brill in the pelagic transformation stage were put into the tank.

On July 5 th a plaice $6.9 \mathrm{~cm}$. ( $2 \frac{3}{4}$ inches) was put in ; it was taken in Cawsand Bay.

On July 21st a turbot 3.5 inches long was put in, taken at the surface in the Sound.

On July 28 th I put in six plaice, 6.5 to $8.5 \mathrm{~cm}$. ( $2 \frac{1}{2}$ to $3 \frac{3}{8}$ inches). These plaice were judged to be of the brood of the year, $i . e$. hatched the preceding January, February, or March.

On September 2nd I took out one of the soles which was dead; it was $9 \cdot 6 \mathrm{~cm}$. long, or $3 \frac{3}{4}$ inches, and must have been not much more or less than six months old.

On October 19th I emptied the tank and measured all the fish in it. The inventory was as follows :

7 plaice: $7 \mathrm{~cm}$. ( $2 \frac{3}{4}$ inches), $12.3 \mathrm{~cm} ., 12.8 \mathrm{~cm} ., 13.0$ c.m.,

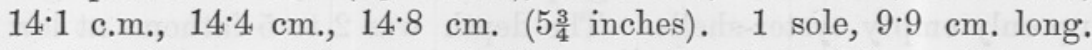
3 brill : $8.0 \mathrm{~cm} ., 8.5 \mathrm{~cm}$, and $10.4 \mathrm{~cm}$. 3 turbot: $6.5 \mathrm{~cm} ., 9.5 \mathrm{~cm}$, $9.9 \mathrm{~cm}$.

There were also three pollack, about $12.3 \mathrm{~cm}$. long, one red mullet and one bream, all young fish of the year.

On April 4th, 1894, several of the fish died, in consequence of a temporary stoppage of the circulation. They were 1 turbot, 10.8

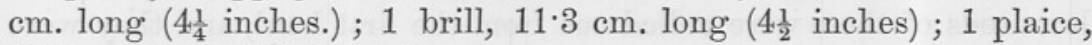
$16 \cdot 7 \mathrm{~cm}$. long ( $6 \frac{3}{4}$ inches).

I have not been able to give sufficient attention to this tank during the past summer to record the size of each specimen that died in it. I examined all the fish in it on December 31st, 1894, and found only the following remaining:-1 sole $14.7 \mathrm{~cm}$. long

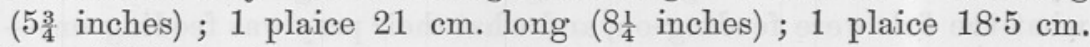
long ( $7 \frac{1}{4}$ inches).

This experiment is obviously a very small contribution to the study of the growth of fishes. Plaice, sole, turbot, and brill evidently do not bear confinement so well as flounders, and it would be better to have a larger number of specimens in a larger tank. Nevertheless the results show observed sizes at known ages, and there can be no doubt that some fish in the sea grow no faster or slower than those. It is shown that a sole may reach from $3 \frac{3}{4}$ to 4 inches when six months old, and may not exceed $5 \frac{3}{4}$ inches when about twenty months old. It is clear, therefore, that soles not differing much from 4. inches in length in spring are probably a year old. This year I 
had an opportunity of examining a large number of soles of about this size.

In the course of some work on which I was engaged for the Essex Technical Instruction Committee I made as careful a study as possible in May and June, 1894, of the fish and marine fauna of the estuary of the Colne and the neighbouring sea channel called the Wallett. On June 8th I went out for a trip in one of the shrimping smacks belonging to Brightlingsea. The boat was 35 to 40 feet long, cutter-rigged and very low in the water. She carried a shrimp trawl of 25 feet beam, with a mesh at the cod end of about $\frac{1}{2}$ inch square. We ran down the Colne with a fair breeze and shot the trawl just beyond the bar, towing eastward, and afterwards took two other hauls further eastward and further from the shore, the last being finished when we were a little to the east of Clacton.

In each haul there were a large number of interesting things besides the shrimps which were the object of the fishing. The red shrimp (Pandalus annulicornis) was most abundant, but there were some brown (Crangon vulgaris) also. The ground at the second haul was hard cultch ; the dredge put over for a few minutes brought up only empty oyster-shells. The depth was 2 to 5 fathoms at low water.

A few fair-sized fish were caught, but none mature. They were plaice, small soles, and dabs. A great number of very small fish were caught. The smallest were dabs and plaice, the latter from 2 to 6 inches long. The most noticeable feature was the very large number of lemon soles 4 or 5 inches long, and doubtless a year old; hundreds of these were culled out from the first haul, and they were almost as numerous in the second and third. Soles of the same range of size, 3 to 5 inches, were also very abundant, but not quite so numerous as the lemon soles. I have never met with so large a collection of yearling soles and lemon soles. I was unable to give my attention to a thorough investigation of this ground to find out what the fish were feeding on, and what their prey was feeding on,in fact, to obtain an explanation of the abundant life in this channel. I opened a young dab 4 inches long, and found it contained a small Amphipod, probably Gammarus. I found a Gadus luscus had its stomach distended with the red shrimp Pandalus.

\section{Notes on Rare or Interesting Specimens.}

During last August mackerel were unusually plentiful in Plymouth Sound, and several large hauls of them were made by means of seines close to the shore below the Laboratory, in the little cove 
known as Tinside. The Laboratory fisherman, watching the hauling of a seine in Barnpool, saw eight shad caught with the mackerel, and these, together with some of the "britt" which escaped from the net, he secured and brought to the Laboratory. I made a careful examination of these fish, and found that they belonged to the species Clupea alosa, having the slender numerous gill-rakers of that species. But in most of the specimens there was a row of dark spots on the side behind the shoulder-spot. Such spots are constant in the other species, C. finta, but, according to Day, have been recorded especially in the young of $C$. alosa. My notes on the specimens are as follows:

(1) Male : $14 \frac{1}{2}$ inches long ; single row of nine rather large spots. Gill-rakers in first arch about 107, seventy on the horizontal portion.

(2) Male : length $13 \frac{3}{4}$ inches; gill-rakers on horizontal portion of first arch, seventy. Nine spots on side in single row.

(3) Male : $13 \frac{1}{4}$ inches; spots in single row, not very distinct; counted six behind the shoulder-spot.

(4) Female : $13 \frac{1}{2}$ inches ; double row of spots on each side, counted twenty-one altogether; spots of one row opposite spaces of the other.

(5) Female : a double row of spots; nine in the upper row, two in lower.

(6) Female : counted seven spots.

(7) Female : five spots.

(8) Female : no spots.

In some cases the spots were symmetrical on the two sides, but in others they were scarcely to be distinguished on one side of the body, although well marked on the other.

In the stomach of one specimen were three half-digested britt, doubtless from the shoals, some of which were taken by the seine and brought up with the shad. These were young sprats, and it was for the sake of feeding on these that both the shad and mackerel were in the Sound.

The weight of the largest shad was $1 \mathrm{lb} .1 \frac{1}{2} \mathrm{oz}$; ; of the smallest, $9 \frac{1}{2} \mathrm{oz}$. As far as I could judge the specimens had previously spawned : the breeding season is stated to be May and June, and it probably spawns in the Tamar.

On September 8th four more specimens of the same species were brought up, taken in a seine on the west side of the Hamoaze.

Auxis Rochei, Günther.-A specimen of this species was obtained on August 13, having been taken with mackerel in a seine at Mount Batten. It was 16 inches long, sex female. The stomach was empty, the ovaries small. Under the microscope the eggs were found to be small, transparent, and yolkless; probably the fish 
had recently spawned. Specimens are stated by Day to have been taken occasionally on the east coast and the south coast of Britain, but not very frequently. He mentions the record of one taken at Looe in 1843, of two in Mount's Bay in 1844, and of one at a later date at Mevagissey by Mr. Dunn. This fish resembles the mackerel in many respects, the chief difference being that the scales are confined to a distinctly limited region behind the head, forming what is called a "corselet."

Orcynus thynnus, Lütken, Thynnus thynnus, Günther.-A specimen of the common tunny 3 feet long was brought to the Laboratory on September 19th. It was caught in mackerel drift-nets some miles from Plymouth Sound, only 18 mackerel being caught in the same haul. It was 3 feet long, and female. The ovaries were small, in an inactive condition, spawning having probably recently occurred. The eggs were very young. Dr. Bassett Smith examined the specimen for parasites, and found Brachilla thynni behind the pectoral fins, and a large number of Trematodes on the gills. The capture of a specimen of this species is not an unusual occurrence off the south-west coast in summer and autumn.

Myliobatis aquila, Cuvier.-A single specimen of this species was brought to the Laboratory on November 1st, probably taken by a trawler, but the exact locality of its capture was not ascertained. It measured $62.5 \mathrm{~cm}$. (2 feet 1 inch) across the pectorals, $40 \mathrm{~cm}$. ( 1 foot 4 inches) from the snout to the end of the conjoined pelvic fins, and $65.5 \mathrm{~cm}$. (2 feet 2 inches) was the length of the tail.

I examined the viscera. The left lobe of the liver was of great size and thickness, and covered the whole abdominal cavity ventrally, the right lobe was much smaller, and dorsal to the left. The stomach, intestine, spleen, and pancreas were as in other Elasmobranchs. The contents of the stomach were much digested, but showed remains of molluses: an operculate foot, apparently of Buccinum, a proboscis of the same, and some pieces of Pecten shell were recognised. The absence of claspers indicated that the specimen was female. The ovaries were smooth, extending nearly the whole length of the body cavity, broad and flat, and joined at their bases across the middle line. The eggs in process of maturation were visible, the specimen being apparently immature. The anterior ends of the oviducts with their openings were very distinct along the sides of the root of the liver just behind the pericardium, but the rest of the tubes were concealed beneath the pericardium. The posterior ends were dilated, and lay over the large kidney (metanephros). There was no distinct egg-shell gland. The species and the other members of the family are generally stated to be viviparous, and Couch's account of the purse which he 
attributed to Myliobatis is too vague and defective to be regarded as important evidence. Members of the allied family Trygonidæ have been recently shown not only to be viviparous, but to nourish their young in the uterus by means of long glandular papillæ of the wall of the uterus, which pass through the spiracles into the stomach of the fœetus.

In my specimen of Myliobatis the abdominal pores were distinct and open behind the aperture of the cloaca. 